
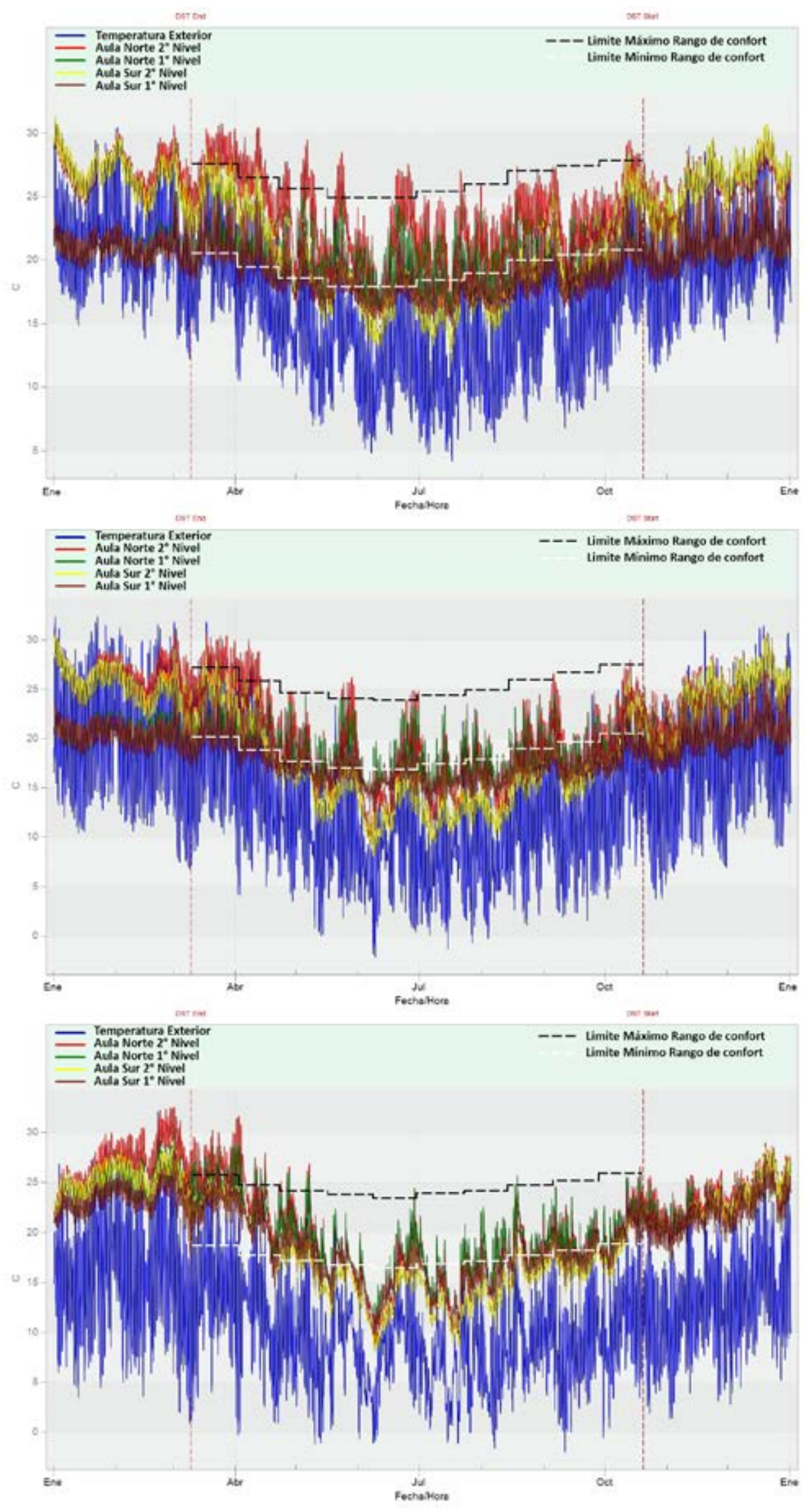

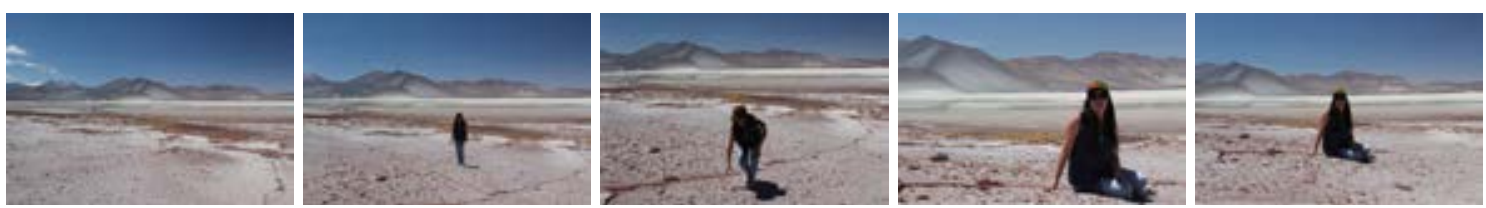

\title{
DISEÑO PASIVO DE AULAS ESCOLARES PARA EL CONFORT TÉRMICO, DESDE UNA PERSPECTIVA PARA EL CAMBIO CLIMÁTICO'
}

\author{
THE PASSIVE DESIGN OF SCHOOL CLASSROOMS FOR THERMAL COMFORT FROM THE \\ PERSPECTIVE OF CLIMATE CHANGE'
}

\author{
Carol Andrea Muñoz
}

RESUMEN

\begin{abstract}
En Chile, la mayoría de los edificios educacionales, no poseen sistemas de calefacción ni de refrigeración que regulen las temperaturas y las condiciones de confort térmico de las aulas. Por tanto, las temperaturas interiores pueden aumentar o disminuir considerablemente en ciertos periodos, impidiendo que los estudiantes realicen sus tareas académicas en un ambiente adecuado. Es por esto que la investigación expuesta se orienta a evaluar el comportamiento térmico, tomando como unidad de análisis, cada uno de los 5 prototipos de aulas con diseño pasivo, de la "Guía de Eficiencia Energética para Establecimientos Educacionales". El estudio logró evidenciar el nivel de confort térmico de las aulas en un contexto climático actual. Además, se establecieron comparaciones, evaluando la vulnerabilidad de estos espacios frente a futuros escenarios de cambio climático, correspondientes a los años 2020, 2050 y 2080. Finalmente, se seleccionaron las aulas con mayor cantidad de horas al año en condición de confort térmico, para que estas puedan actuar como referentes en nuevos proyectos educativos.
\end{abstract}

Palabras clave: arquitectura escolar, aulas, cambio climático, temperatura ambiental, Chile.

\section{ABSTRACT}

In Chile, the vast majority of educational buildings possess neither heating nor cooling systems that regulate temperature and thermal comfort in classrooms. Therefore, indoor temperatures can increase or decrease considerably in specific periods during the school year, thus preventing students from carrying out their academic activities in a suitable environment. For this reason, the present investigation evaluated thermal behavior and took as the unit of analysis each of the five passive design classroom prototypes from the "Energy Efficiency Guide for Educational Establishments" (Guía de Eficiencia Energética para Establecimientos Educacionales). The study demonstrated the level of thermal comfort in the classrooms in the current climate context. Additionally, comparisons were made to evaluate the vulnerability of these spaces in the face of future climate change scenarios for the years 2020, 2050 and 2080. Lastly, the classrooms with the highest number of hours of thermal comfort were selected so that these can act as models for new educational projects.

Keywords: school architecture, classrooms, climate change, environmental temperature, Chile.

Artículo recibido el 23 de abril de 2018 y aceptado el 19 de noviembre de 2018 DOI: https://doi.org/10.22320/07196466.2018.36.054

[1] Este trabajo se basa en los resultados de la investigación de la tesis de Magister en Hábitat Sustentable y Eficiencia Energética de la Universidad del Bío Bío, Concepción

[2] Independiente, Concepción, Chile.carolm2610@gmail.com 
En los últimos años, innumerables investigaciones han revelado la creciente contaminación atmosférica y la escasez de recursos energéticos, lo que ha motivado al país a enfocarse en el ahorro y eficiencia. Los edificios son causantes de un gran porcentaje de consumo energético, debido principalmente a la necesidad de satisfacer los requerimientos de confort de los ocupantes (UNEP, 2012).

Sin embargo, los edificios educacionales en Chile no generan grandes consumos energéticos, puesto que la mayoría no posee sistemas de calefacción y refrigeración que regulen las temperaturas interiores. El problema son las condiciones de confort térmico y la mala calidad del aire al interior de las aulas, donde los estudiantes pasan largas horas en un ambiente con temperaturas extremas, lo cual impide que realicen sus tareas académicas en condiciones adecuadas.

La Agencia Chilena de Eficiencia Energética (AChEE), en conjunto con el Centro de Investigación en Tecnologías de la Construcción - Universidad del Bío-Bío (CITEC UBB), desarrolló en 2012 la "Guía de Eficiencia Energética para Establecimientos Educacionales" (GEEEduc), que constituye una guía para el diseño de aulas educativas con alto desempeño energético y estándares superiores de confort ambiental a lo largo del país. En ella, se proponen 5 alternativas de diseño de prototipos de "aulas integrales" que incorporan estrategias de diseño para mejorar las condiciones de confort térmico, lumínico, acústico y de calidad del aire de las aulas.

De los 5 prototipos de "aulas integrales" que entrega la guía, 2 de ellos fueron evaluados. El análisis comprende el cálculo de demanda energética de calefacción y refrigeración, en el supuesto de que las aulas poseen sistemas de acondicionamiento para alcanzar un rango de confort entre 20 y $26^{\circ} \mathrm{C}$, lo que no se condice con las condiciones reales de operación de aulas escolares en Chile.

Por lo tanto, es necesario definir el rango de confort térmico para aulas escolares, ya que no existen en el país normas apropiadas en ese sentido: "Las regulaciones actuales no han sido suficientes para proporcionar a los niños un ambiente de aprendizaje cómodo, sobre todo los que vienen de bajos niveles socioeconómicos" (Trebilcock et al., 2017:468). Diversos estudios a nivel mundial muestran la relación directa entre la calidad del ambiente interior en un aula y el aprendizaje de los alumnos, donde la temperatura desempeña un papel fundamental, influyendo en el rendimiento por problemas de distracción o mala comprensión. Más aún, existen estudios que reflejan la estrecha relación del confort térmico con el proceso de la memoria y la atención (Batiz et al., 2009).

En los últimos años, investigaciones en edificios educacionales en Chile han evidenciado la mala calidad del ambiente interior de las aulas, demostrando que los estudiantes están expuestos a una amplia gama de temperaturas con fuertes variaciones diarias y estacionales (Trebilcock et al., 2016). Estudios de campo realizados en periodo de invierno, en escuelas del sur de país, registraron una diferencia de entre los $-5,4^{\circ} \mathrm{C}$ y $-10,4^{\circ} \mathrm{C}$, entre la temperatura efectiva y temperatura operativa en el lugar, lo que se reflejó en un elevado porcentaje de insatisfacción, del 71,4\%. En consecuencia, en los estudios recién mencionados, ninguna escuela cumple con 
los estándares internacionales indicados por la norma ISO7730 o la ASHRAE 55 para esta época del año (Molina y Veas, 2012).

Esta situación se complica si se piensa que el confort térmico está ligado a diversos factores influyentes en la calidad del ambiente de un aula con diseño pasivo. Uno de esos factores es la calidad del aire, donde la ventilación natural cumple un rol fundamental. En las aulas, esta ventilación se genera principalmente por la apertura de ventanas, provocando un enfriamiento excesivo en los meses más fríos; además, si el edificio educacional está ubicado en zonas urbanas y sectores ruidosos, el confort acústico se ve perjudicado. Por tanto, la solución no es óptima para el entorno de enseñanza (Armijo, Whitman y Casals, 2011). En conclusión, se debe apuntar directamente al bienestar de los estudiantes, entregando mejores condiciones para su aprendizaje, de manera de contribuir a que se incremente la productividad, la atención y la concentración de los estudiantes, y a que disminuyan, en contraparte, los niveles de ausentismo por problemas de salud asociados a las malas condiciones ambientales.

Asimismo, el problema de confort térmico se verá afectado por futuros escenarios de cambio climático, debido a las consecuencias actuales de un calentamiento global de $1^{\circ} \mathrm{C}$, según se indica en un nuevo informe especial del IPCC (Intergovernmental Panel on Climate Change), donde se ha observado un aumento en promedio de la temperatura global, aumento de precipitaciones en algunas regiones y drástica disminución en otras, entre otros cambios. Este informe expone la necesidad de limitar el calentamiento global a $1,5^{\circ} \mathrm{C}$, lo cual evitaría una serie de impactos ambientales, aun cuando los efectos y los costos serán peores que lo esperado (IPCC, 2018).

Los estudios desarrollados en Chile en los últimos años dan cuenta de un aumento en las temperaturas, particularmente en las zonas interiores del norte centro y sur del país. "En la zona central y sur, las olas de calor aumentan a una razón de 3 por cada 100 años. Las temporadas de 2011-12, 2014-15 y 2015-16, han sido las que han registrado el mayor número de olas de calor, aumentando en un 40\%" (Dirección Meteorológica de Chile, 2016 2). Durante el año 2017, la situación fue similar, manifestándose temperaturas máximas medias en extremo cálidas, en prácticamente todo el país. Destacan, en este sentido, las ciudades de Santiago y Curicó donde se presentaron olas de calor de mayor frecuencia, duración e intensidad (Dirección Meteorológica de Chile, 2018: 12). Por consiguiente, es necesario preparase para el futuro y las nuevas condiciones climáticas que están cambiando constantemente, generando proyectos que logren un estándar aceptable a lo largo de su vida útil.

Es por ello que la presente investigación se centró en analizar el diseño pasivo de los prototipos de "aulas integrales" de la "Guía de Eficiencia Energética para Establecimientos Educacionales" (CITEC UBB, 2012), en tres zonas climáticas de Chile, en base a criterios de confort térmico de los estudiantes, tanto en un contexto climático actual, como en futuros escenarios de cambio climático, para que estos últimos puedan actuar como referentes en nuevos proyectos educativos.

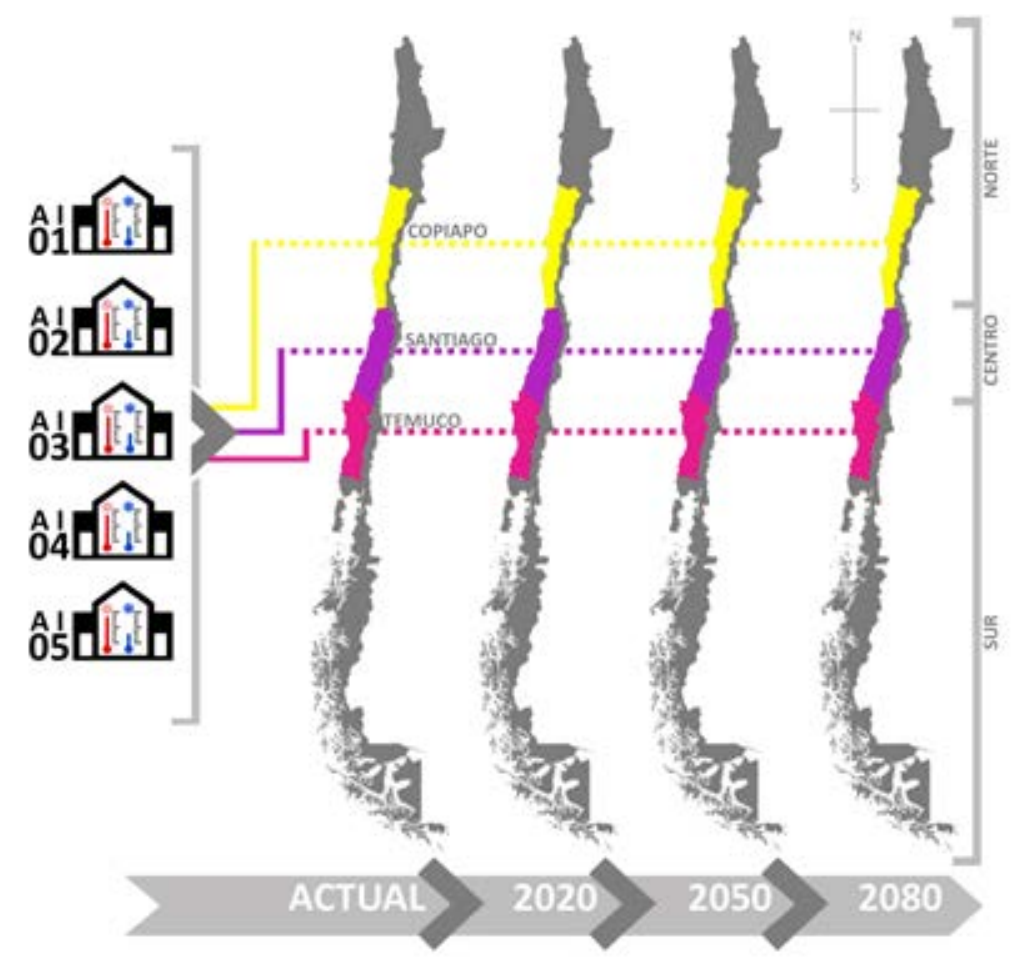

Figura 1 Esquema Metodológico. Fuente: Elaboración del autor 


\begin{tabular}{|c|c|}
\hline $\begin{array}{l}\text { Cargas internas (sólo durante } \\
\text { período de ocupación) }\end{array}$ & $\begin{array}{l}\text { Alumnos } 66 \mathrm{~W} \text {; adultos } 108 \mathrm{~W} \text {; iluminación artificial aulas } 300 \text { lux }-11,25 \mathrm{~W} / \mathrm{m} 2 \text {; equipo informático } 6 \mathrm{~W} / \\
\mathrm{m} 2 \text {, densidad ocupacional } 45 \text { alumnos por aula }+1 \text { profesor. }\end{array}$ \\
\hline Período de ocupación & Lunes a viernes, de $8: 00$ a 12:00 y 13:00 a 16:00 horas. \\
\hline Períodos de vacaciones & Estación de verano, en los meses de Enero y Febrero. \\
\hline lluminación & Mínima de $300 l u x$ a la altura del plano de trabajo. \\
\hline $\begin{array}{l}\text { Ventilación (En base a } \\
\text { requerimientos del DS } 560 \text { del } \\
\text { MINEDUC) }\end{array}$ & $\begin{array}{l}\text { Se consideraron } 5 \text { ach en período de ocupación. En verano se consideró ventilación adicional por } \\
\text { apertura de ventanas de } 2 \text { ach cuando la temperatura interior supera los } 23^{\circ} \mathrm{C} \text {, de lunes a viernes entre las } \\
\text { 8:00 y las } 16: 00 \text { horas. }\end{array}$ \\
\hline $\begin{array}{l}\text { Los muros exteriores y la losa de } \\
\text { entrepiso }\end{array}$ & Fueron considerados adiabáticos, excepto el muro que posee ventanas. \\
\hline Muros de hormigón & Se contempló un estuco de e: $10 \mathrm{~mm}$. \\
\hline Revestimiento de cubierta & Se consideró plancha de zinc alum. \\
\hline
\end{tabular}

Tabla 1 Parámetros generales de simulación. Fuente: CITEC UBB, 2012.

\begin{tabular}{|c|c|c|c|c|}
\hline \multicolumn{2}{|l|}{ ZONA CLIMÁTICA } & 3NVT & $5 \mathrm{Cl}$ & 7SI \\
\hline \multicolumn{2}{|l|}{ Ciudad } & Copiapó & Santiago & Temuco \\
\hline \multicolumn{2}{|l|}{ Zona térmica } & $\mathrm{ZT} 2$ & ZT3 & ZT5 \\
\hline \multirow[t]{3}{*}{ Valor U } & $\operatorname{Muro}\left(\mathrm{Wm} 2 /{ }^{\circ} \mathrm{C}\right)$ & 1,5 & 1,5 & 0,3 \\
\hline & Piso $\left(\mathrm{Wm} 2 /{ }^{\circ} \mathrm{C}\right)$ & 3,8 & 3,8 & 0,7 \\
\hline & Techo $\left(\mathrm{Wm} 2 /{ }^{\circ} \mathrm{C}\right)$ & 0,47 & 0,47 & 0,18 \\
\hline \multirow[t]{3}{*}{ Aislación Térmica } & Espesor Muro (mm) & 20 & 20 & 130 \\
\hline & Espesor Techo (mm) & 80 & 80 & 220 \\
\hline & Espesor Piso (mm) & 0 & 0 & 50 \\
\hline \multicolumn{2}{|l|}{ Tipo de vidrio } & DVH & DVH & DVH \\
\hline \multicolumn{2}{|c|}{ Superficie vidriada fachada } & $23 \%$ & $23 \%$ & $23 \%$ \\
\hline \multicolumn{2}{|l|}{ Infiltración } & $0,5 \mathrm{ach}$ & $0,5 \mathrm{ach}$ & $0,5 \mathrm{ach}$ \\
\hline \multicolumn{2}{|l|}{ Ventilación base } & 5 ach & 5 ach & 5 ach \\
\hline \multicolumn{2}{|c|}{ Ventilación adicional verano (Temp. Int. $\geq 23^{\circ} \mathrm{C}$ ) } & $2 \mathrm{ach}$ & $2 \mathrm{ach}$ & 2 ach \\
\hline
\end{tabular}

Tabla 2 Parámetros de simulación, según zona climática. Fuente: CITEC UBB, 2012.

\section{MÉTODO}

Mediante simulación térmica a través del software Design Builder, se identificó el nivel del confort térmico en los 5 prototipos de "aulas integrales", analizando la influencia del clima para las 3 zonas climáticas, según NCh1079.Of2008, que corresponden al clima de 3 ciudades del país: zona Norte Valles Transversales, representada por la ciudad de Copiapó; zona Central Interior, representada por la ciudad de Santiago y zona Sur Interior, representada por la ciudad de Temuco. Estas, a su vez, representan las macrozonas norte, central y sur.
En un segundo análisis, se realizó una comparación térmica de los 5 prototipos de "aulas integrales", variando su orientación (norte o sur, oriente o poniente) y estudiando, en especial, el comportamiento del confort térmico al interior de las aulas durante el transcurso de un año.

En seguida, se evaluó el prototipo de "aulas integrales" con mayor nivel de confort y disconfort térmico, manteniendo los parámetros establecidos por la "Guía de 
Eficiencia Energética para Establecimientos Educacionales" y sustituyendo los archivos climáticos actuales por escenarios climáticos futuros, en los años 2020, 2050 y 2080. Con cada una de las valoraciones realizadas se reveló la importancia del estudio del confort térmico para el bienestar de los estudiantes, en las aulas de los edificios educacionales del país.

Para el análisis de cada prototipo, se consideró un aula en primer nivel y un aula en segundo nivel. Además, estas dos aulas fueron evaluadas en dos orientaciones, oriente y poniente o norte y sur, dependiendo del diseño. En total, se analizaron 4 aulas por cada prototipo. Los 5 prototipos reflejan características generales similares, con aulas de una superficie de $6 \mathrm{~m} \times 9 \mathrm{~m}$ y una altura de $3 \mathrm{~m}$. Para la materialidad de la envolvente, se consideró hormigón armado de los siguientes espesores: muros (e: $200 \mathrm{~mm}$ ), piso (e: $100 \mathrm{~mm}$ ), losa de entrepiso (e: $170 \mathrm{~mm}$ ) y losa de techumbre (e: $120 \mathrm{~mm})$.

Las tres zonas climáticas de Chile, definidas por la NCh1079.Of2008, que fueron seleccionadas aquí pertenecen a la zona interior del país, donde en los últimos años se ha registrado una tendencia al aumento de temperaturas y donde se espera un posible sobrecalentamiento, que afectará considerablemente las edificaciones existentes. Estas zonas climáticas están incorporadas en la simulación térmica, mediante un archivo climático de una ciudad representativa.

La primera evaluación se llevó a cabo con un "archivo climático actual" en formato EPW, que corresponde a los archivos utilizados generalmente en las simulaciones, cuyos datos están basados en valores medios del clima para el período 1960 al 1991. Posteriormente, se realizó evaluaciones con archivos climáticos que representaban una proyección futura del clima. Esta información fue obtenida de investigaciones referentes a las influencias del cambio climático en Chile (Rubio-Bellido y Pérez-Fargallo, 2016). A partir de tales estudios, los "archivos climáticos actuales" de 9 ciudad representativas para cada una de las 9 zonas climáticas, fueron transformados, por medio del modelo HadCM3, obteniéndose así conjuntos de datos que representaron el clima promedio más probable esperado para los años 2020, 2050 y 2080. Finalmente, se determinaron, en total, 3 escenarios climáticos actuales y 9 escenarios climáticos futuros, que componen una base de datos de 12 archivos climáticos, para ser analizados.

Los límites de la zona de confort se precisan según el modelo adaptativo del estándar ASHRAE 55-2017 para edificios ventilados naturalmente. Para la evaluación se optó por el método de límites del $80 \%$ de aceptabilidad, donde el rango de la temperatura de confort superior e interior se determina usando las siguientes fórmulas:

Límite superior de zona de confort $=0.31 \times$ Tme $+21,3$

Límite inferior de zona de confort $=0.31 \times$ Tme $+14,3$

Donde, Tme: corresponde a la temperatura media exterior, la cual fue calculada obteniendo el promedio mensual de todas las temperaturas exteriores medias diarias.

\section{RESULTADOS}

\section{Análisis de las aulas en condición climática actual}

De todos los datos obtenidos, y que entrega el software, se analizó la temperatura operativa correspondiente al valor medio entre la temperatura del aire $y$ la temperatura radiante media. Con esta información, se calculó el porcentaje de horas en que la temperatura interior de cada aula se encuentra dentro del rango de confort térmico a lo largo del año. Esto para las cuatro aulas que presenta cada uno de los cinco prototipos.

Una vez realizado el análisis de las cuatro aulas por cada uno de los prototipos, como se muestra en las Figura 2, 3 y 4, se clasificaron y compararon según la ubicación y orientación de cada aula, con el objetivo de evaluar esta condicionante y su influencia en el comportamiento térmico. Finalmente, con los resultados obtenidos, se obtuvo el prototipo que logró un mejor comportamiento térmico, como también el más deficiente, por cada una de las tres zonas climáticas.

\section{Zona Norte Valles Transversales}

Mayor confortabilidad térmica: Prototipo aula integral $\mathrm{N}^{\circ} 4$ a. Se obtuvo un resultado promedio entre las aulas de $79 \%$ de horas, donde la temperatura interior se encuentra dentro del rango de confort térmico.

Menor confortabilidad térmica: Prototipo aula integral $\mathrm{N}^{\circ} 2$ a. Se obtuvo un resultado promedio entre las aulas de $68 \%$ de horas, donde la temperatura interior se encuentra dentro del rango de confort térmico.

\section{Zona Central Interior}

Mayor confortabilidad térmica: Prototipo aula integral $\mathrm{N}^{\circ} 1 \mathrm{~b}$. Se obtuvo un resultado promedio entre las aulas de $63 \%$ de horas, donde la temperatura interior se encuentra dentro del rango de confort térmico.

Menor confortabilidad térmica: Prototipo aula integral $\mathrm{N}^{\circ} 2 \mathrm{~b}$. Se obtuvo un resultado promedio entre las aulas de $54 \%$ de horas, donde la temperatura interior se encuentra dentro del rango de confort térmico.

\section{Zona Sur Interior}

Mayor confortabilidad térmica: Prototipo aula integral $\mathrm{N}^{\circ} 5 \mathrm{c}$. Se obtuvo un resultado promedio entre las aulas de $64 \%$ de horas, donde la temperatura interior se encuentra dentro del rango de confort térmico.

Menor confortabilidad térmica: Prototipo aula integral $\mathrm{N}^{\circ} 2 \mathrm{c}$. Se obtuvo un resultado promedio entre las aulas de $50 \%$ de horas, donde la temperatura interior se encuentra dentro del rango de confort térmico. 
Prototipo de aula integral $\mathrm{N}^{\circ} 1$

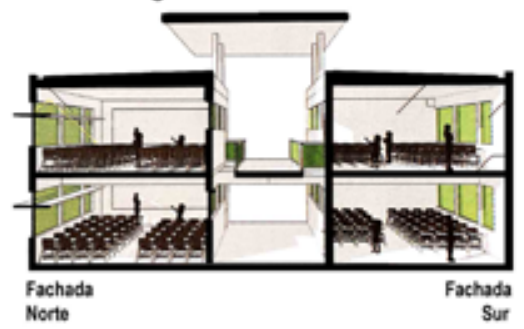

Prototipo de aula integral $\mathrm{N}^{\circ} 2$
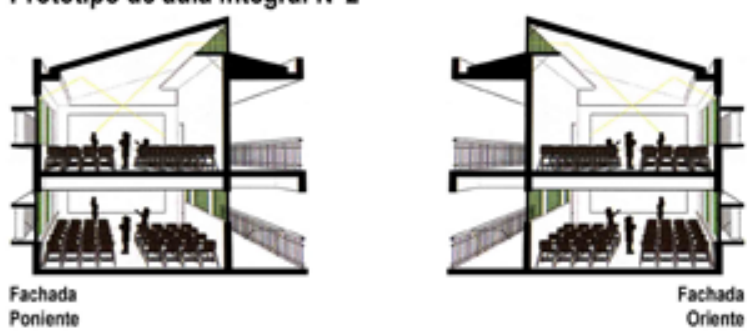

Prototipo de aula integral $\mathrm{N}^{\circ} 3$
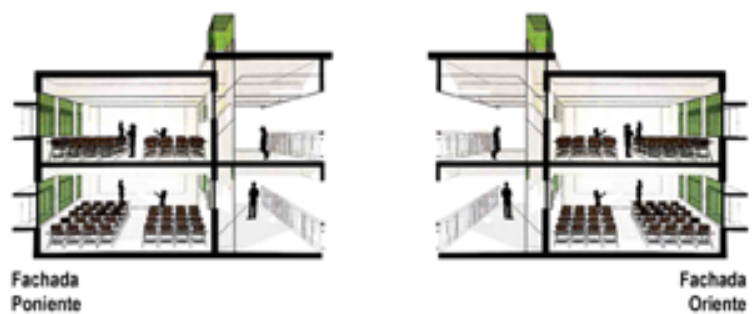

Prototipo de aula integral $N^{\circ} 4$
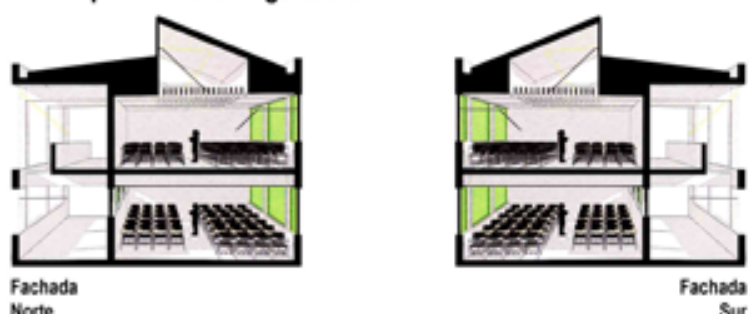

Prototipo de aula integral $N^{\circ} 5$
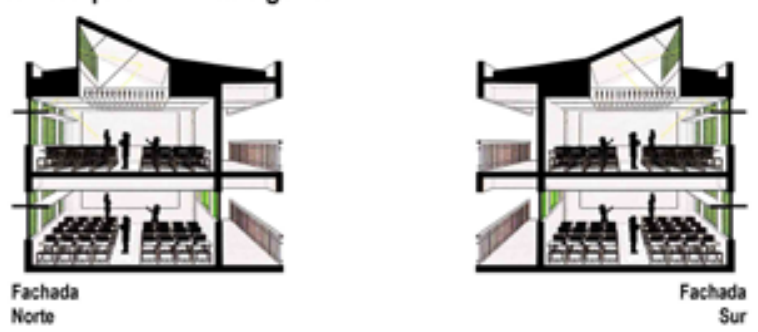

Comparación de confort y disconfort térmico en las aulas.

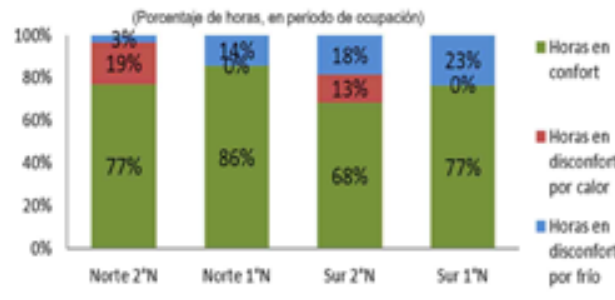

Comparación de confort y disconfort termico en las aulas.

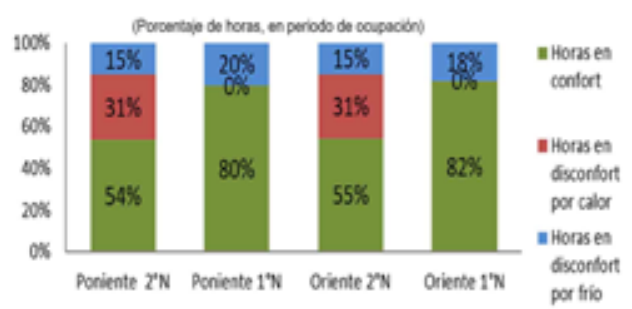

Comparación de confort y disconfort termico en las aulas.

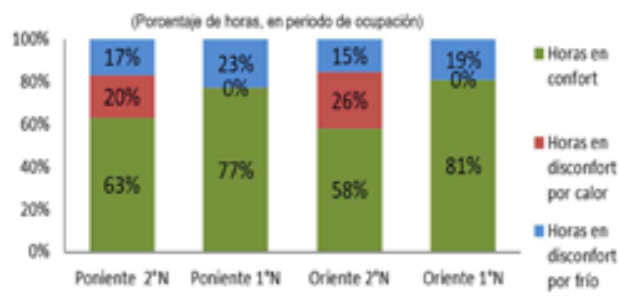

Comparación de confort y disconfort tórmico en las aulas.

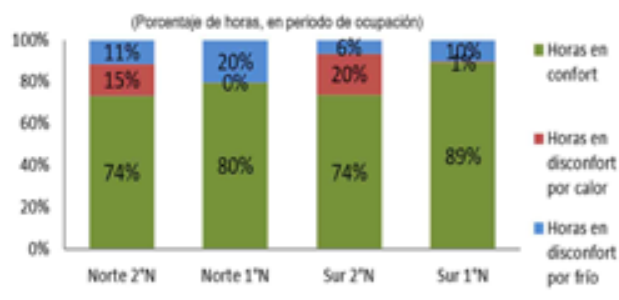

Comparación de confort y disconfort térmico en las aulas.

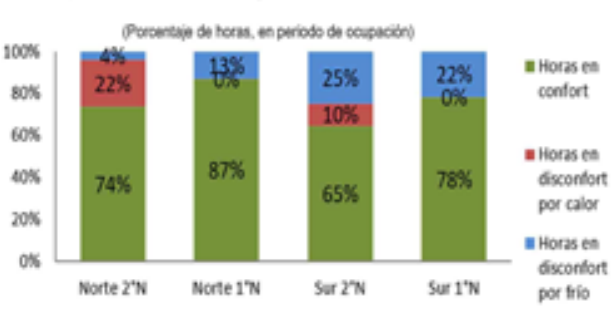

Figura 2 Análisis de aulas en condición climática actual - Zona Norte Valles Transversales. Fuente: Elaboración de la autora. 
Prototipo de aula integral $N^{\circ} 1$

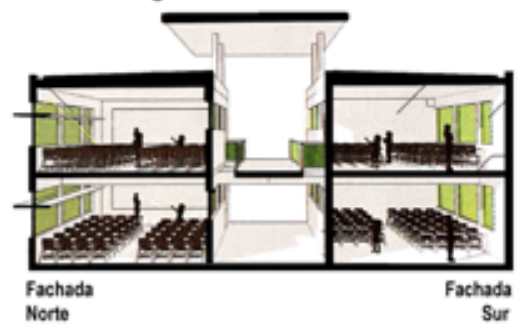

Prototipo de aula integral $\mathrm{N}^{\circ} 2$
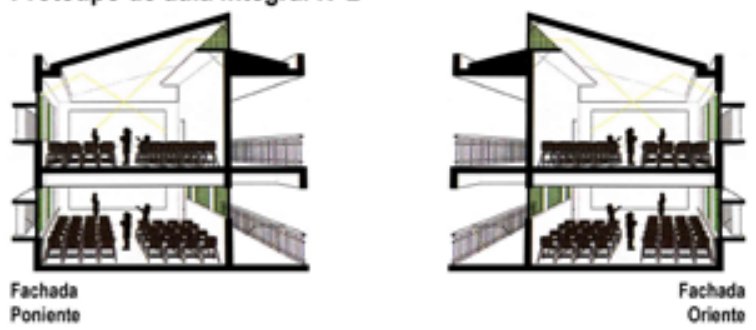

Prototipo de aula integral $\mathrm{N}^{\circ} 3$

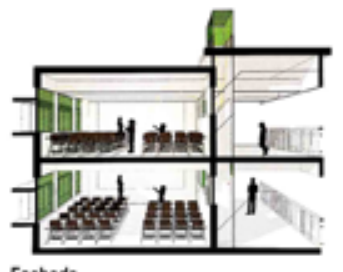

Fachada

Poniente

Prototipo de aula integral $\mathrm{N}^{\circ} 4$

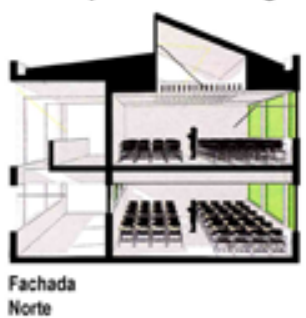

Prototipo de aula integral N5
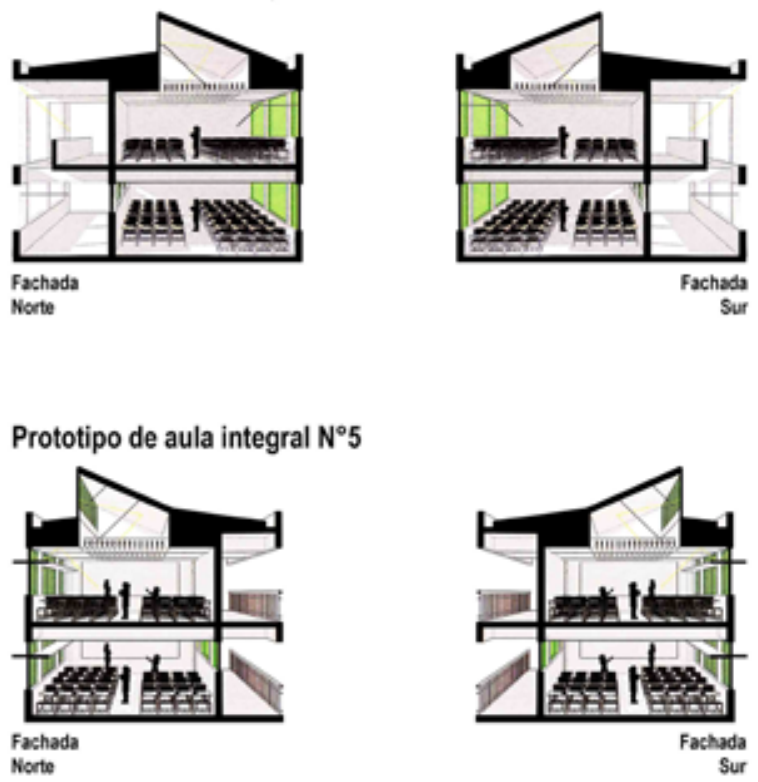

Comparación de confort y disconfort térmico en las aulas.

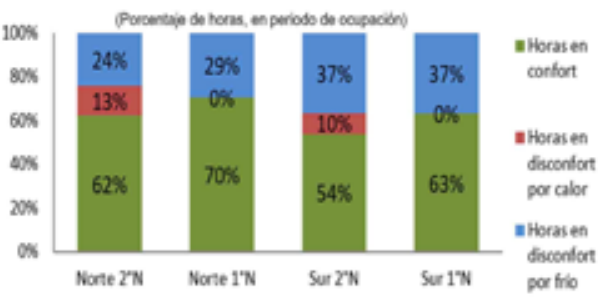

Comparación de confort y disconfort térmico en las aulas.

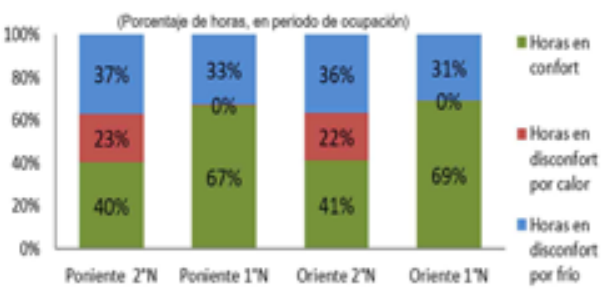

Comparación de confort y disconfort tiermico en las aulas.

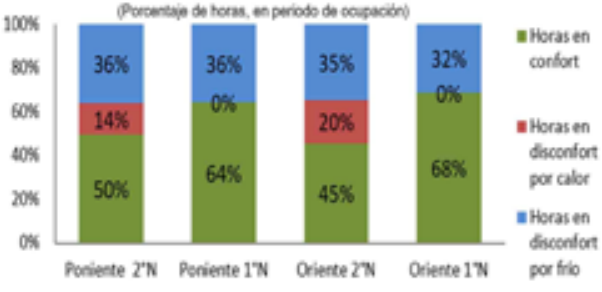

Comparación de confort y disconfort térmico en las aulas.

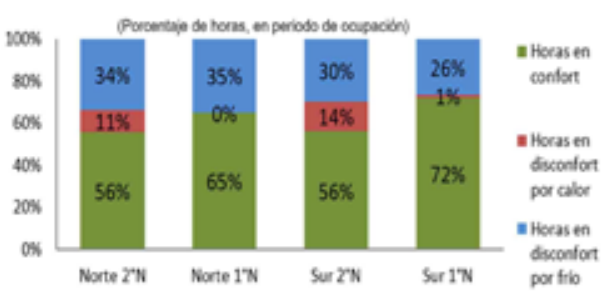

Comparación de confort y disconfort térmico en las aulas.

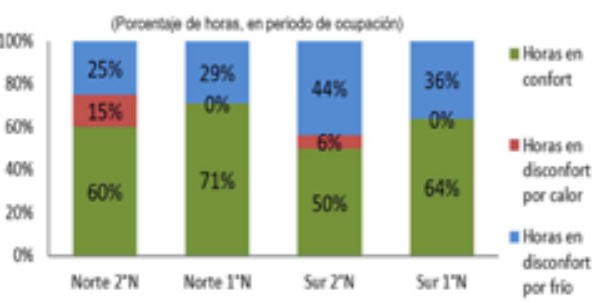

Figura 3 Análisis de aulas en condición climática actual - Zona Central Interior. Fuente: Elaboración de la autora. 
Prototipo de aula integral $\mathrm{N}^{\circ} 1$

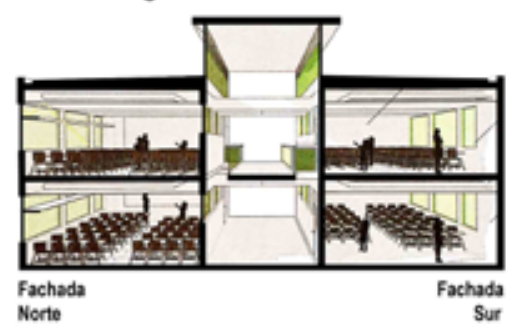

Prototipo de aula integral $\mathrm{N}^{\circ} 2$
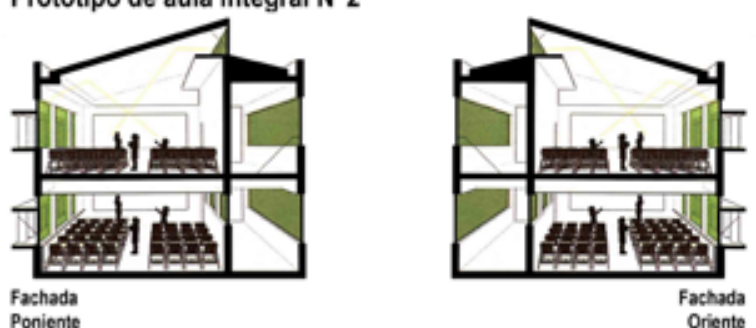

Prototipo de aula integral $\mathrm{N}^{\circ} 3$

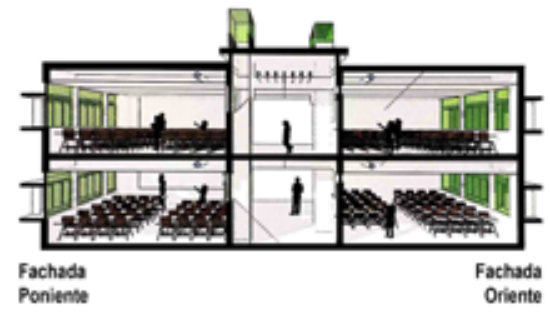

Prototipo de aula integral $\mathrm{N}^{\circ} 4$
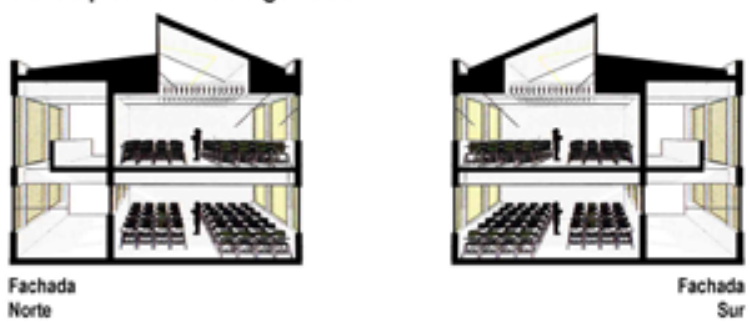

Prototipo de aula integral $\mathrm{N}^{\circ} 5$

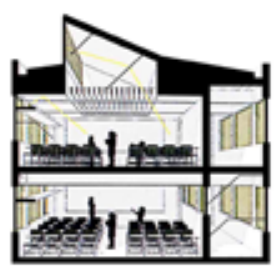

Fachada
Norte

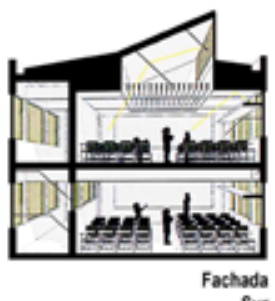

Comparación de confort y disconfort térmico en las aulas.

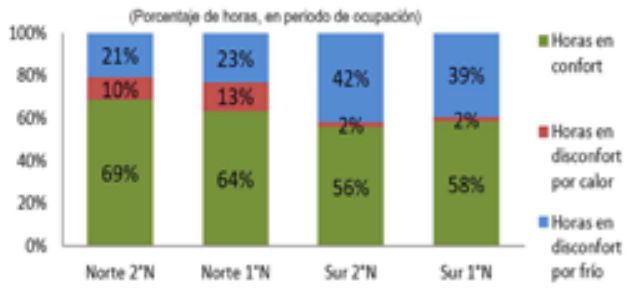

Comparación de confort y disconfort térmico en las aulas.

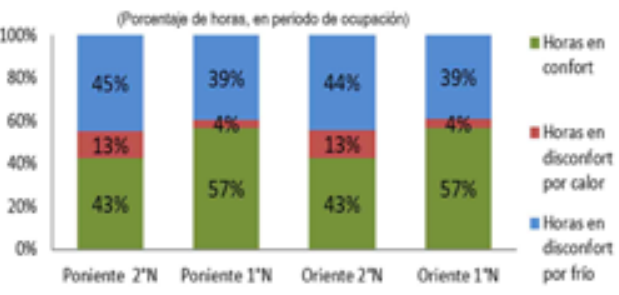

Comparación de confort y disconfort térmico en las aulas.

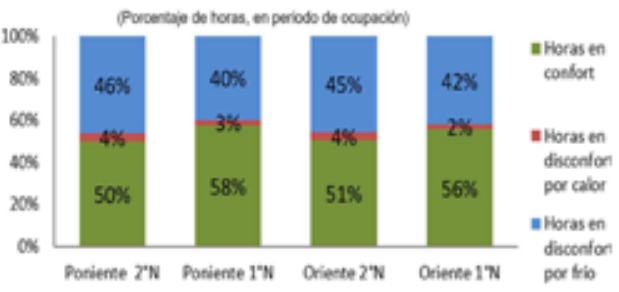

Comparación de confort y disconfort térmico en las aulas.

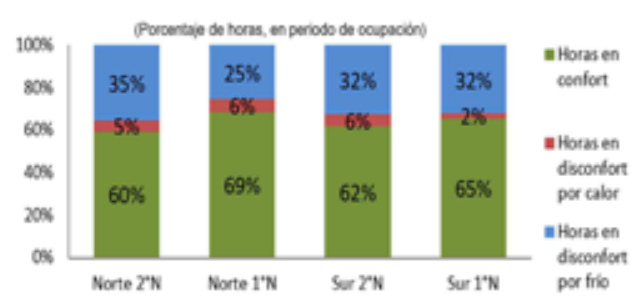

Comparación de confort y disconfort térmico en las aulas.

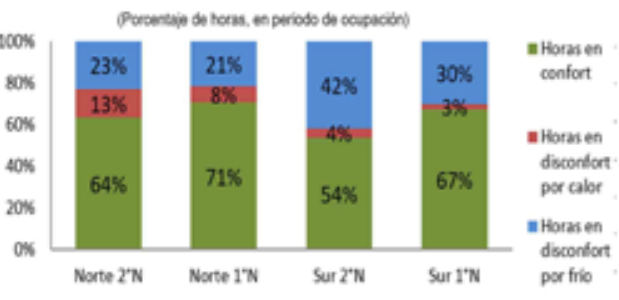

Figura 4 Análisis de aulas en condición climática actual - Zona Sur Interior. Fuente: Elaboración de la autora. 


\section{Análisis de las aulas en proyecciones de cambio climático}

Efectuados todos los análisis anteriores, se puede concluir cuál es el prototipo con mejor comportamiento térmico y el prototipo con el comportamiento térmico más deficiente, por cada una de las tres zonas climáticas. En estas evaluaciones se muestra el porcentaje de disconfort, que corresponde a la cantidad de horas en que la temperatura al interior se encuentra fuera del rango de confort térmico, ya sea por calor o por frío. Esto para cada una de las cuatro aulas que presenta cada uno de los prototipos seleccionados anteriormente. A su vez, se proyecta el clima de las tres zonas estudiadas, estableciendo una comparación entre las aulas en condición climática actual y proyecciones climáticas, correspondiente a los años 2020, 2050 y 2080.
Análisis de la temperatura interior de las aulas y rango de confort térmico para la Zona Norte Valles Transversales:

En la zona norte, como se muestra en la Figura 5, las temperaturas son más altas que en las otras zonas, por tanto, existe un alto riesgo de sobrecalentamiento al interior de las aulas, más todavía si se genera una proyección futura del clima. Lo anterior se produce principalmente en el prototipo $\mathrm{N}^{\circ} 4$, que presenta los mejores resultados en un contexto climático actual, pero cuya proyección en el tiempo, disminuye su porcentaje de confort, con lo cual sus resultados terminan acercándolo al del prototipo peor evaluado.

Esta situación se genera por las ganancias solares en los meses calurosos, donde la orientación de cada aula requiere de un adecuado diseño de ventanas. En el
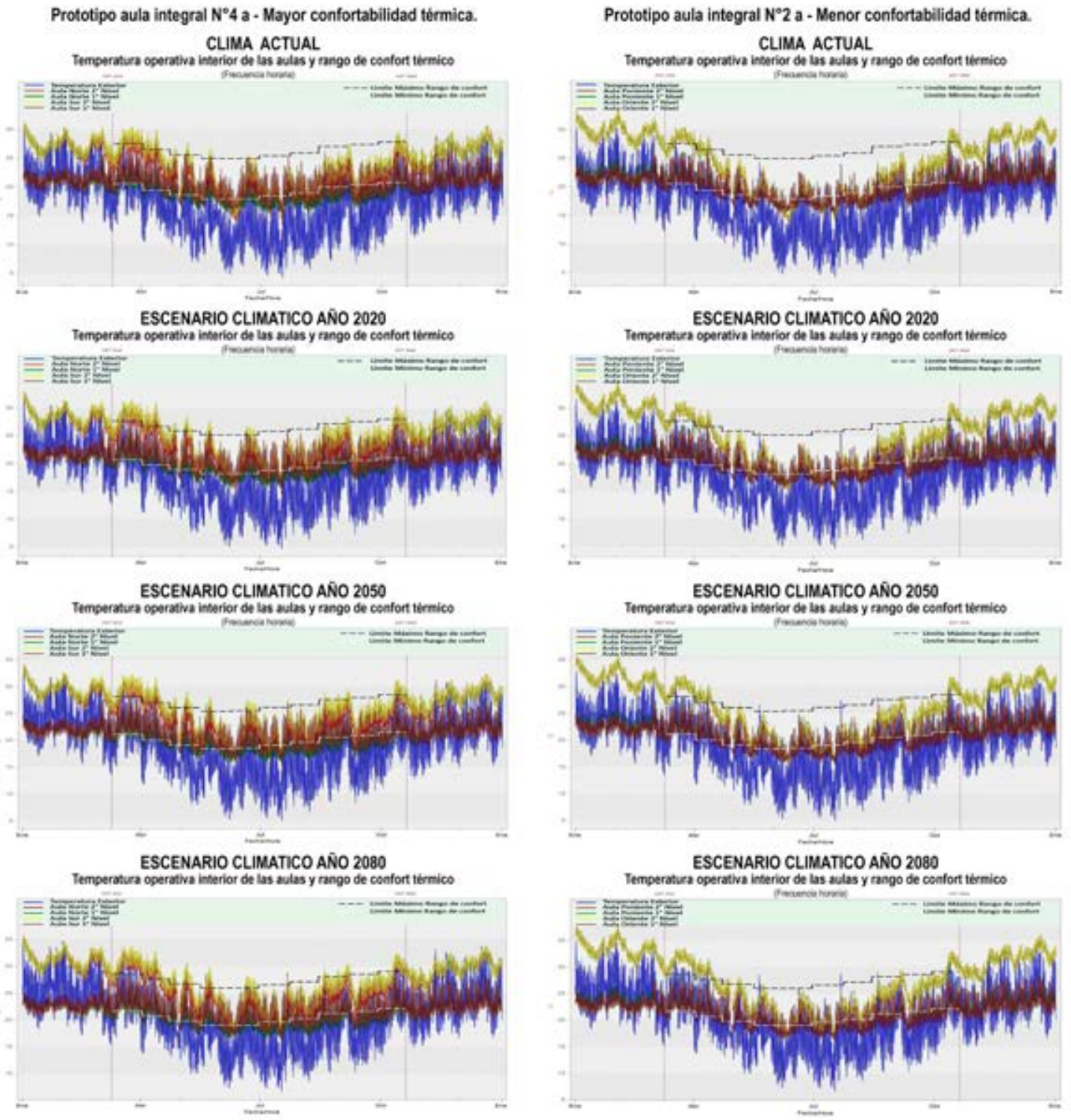

Figura 5 Análisis de la temperatura interior de las aulas y rango de confort térmico - Zona Norte Valles Transversales. Fuente: Elaboración de la autora. 
prototipo $\mathrm{N}^{\circ} 4$, las aulas ubicadas hacia el sur, muestran un pasillo exterior que genera un control solar en las ventanas norte, ya que actúa como alero. Aun así, en las aulas con orientación norte, las ventanas principales no presentan protecciones solares y existe una gran lucarna en la cubierta que provoca un exceso de captación solar.

Análisis de los prototipos de aula con mayor y menor confortabilidad térmica para la Zona Norte Valles Transversales:

El análisis de las aulas en proyecciones de cambio climático, para la Zona Norte Valles Transversales (Figura 6), ocurrieron dos escenarios. El prototipo de aula $\mathrm{N}^{\circ} 4$, en condición climática actual, muestra el mejor resul- tado respecto al porcentaje de confortabilidad térmica. Este porcentaje disminuye en el tiempo de un $79 \%$ a un $72 \%$ para el año 2080 . Por el contrario, el prototipo de aula $\mathrm{N}^{\circ} 2$, en condición climática actual, exhibe el peor resultado para esta zona, respecto al porcentaje de confortabilidad térmica. Dicho porcentaje aumenta levemente en el tiempo, de un $68 \%$ a un $69 \%$ para el año 2080. Ambos prototipos, al ser proyectados en el tiempo, logran disminuir la brecha que se genera entre sus resultados.

Análisis de la temperatura interior de las aulas y rango de confort térmico para la Zona Central Interior:

En la zona centro, como se grafica en la Figura 7, las temperaturas máximas son tan altas como en la zona
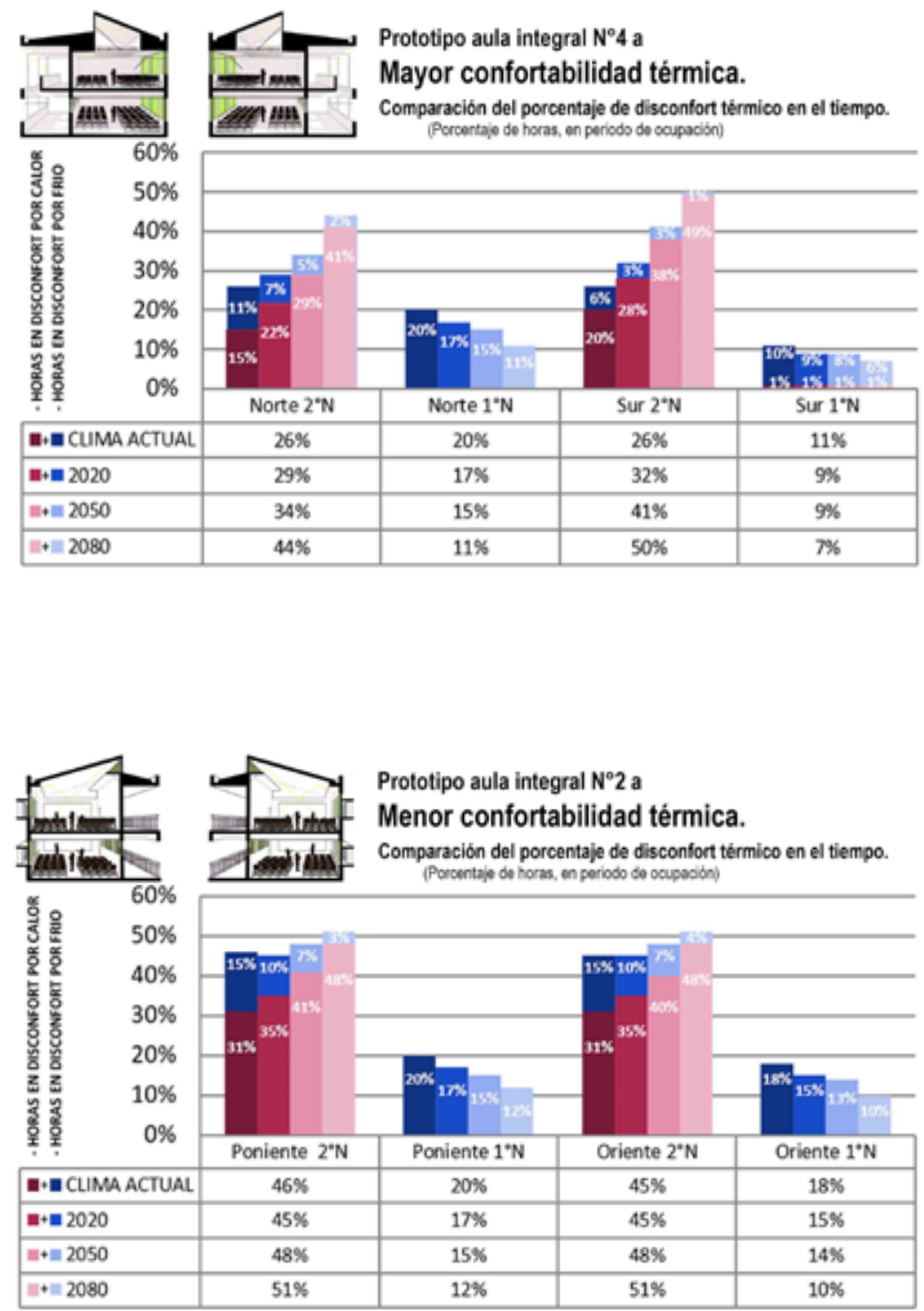
norte, y en los periodos de invierno, bajan considerablemente. En estas circunstancias, los prototipos con mejor y peor resultados lograron mejorar en el tiempo, transformándose en la zona más favorecida con los cambios climáticos.

Ambos prototipos, independiente de su orientación, presentaron altas temperaturas interiores en los meses más calurosos del año, con sobrecalentamiento en el segundo nivel, pero por un corto periodo de tiempo. Lo realmente influyente fue el aumento de temperaturas exteriores en los meses más fríos, lo que produjo que las temperaturas al interior de las aulas lograran alcanzar los rangos de confort térmico.
Análisis de los prototipos de aula con mayor y menor confortabilidad térmica para la Zona Central Interior:

En la Figura 8, las aulas en proyecciones de cambio climático para la Zona Central Interior, en ambos prototipos, mejoran su condición de confort. El prototipo de aula $\mathrm{N}^{\circ} 1$, en condición climática actual, expone el mejor resultado respecto al porcentaje de confortabilidad térmica. Tal porcentaje aumenta con el tiempo, de un $63 \%$ a un $65 \%$ para el año 2080 . Por el contrario, el prototipo de aula $\mathrm{N}^{\circ} 2$, en condición climática actual, muestra el peor resultado para esta zona, respecto al porcentaje de confortabilidad térmica. Este porcentaje aumenta en la proyección, de un 54\% a un 59\% para el

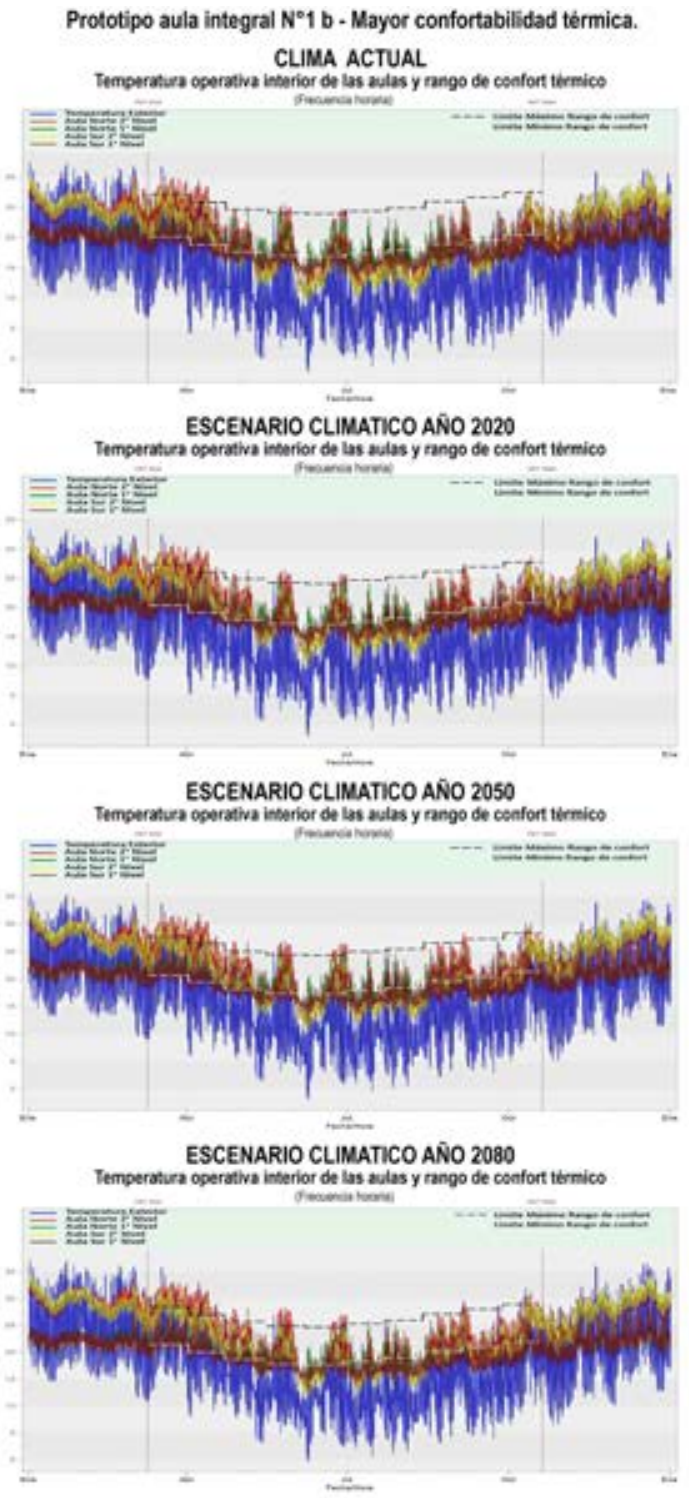

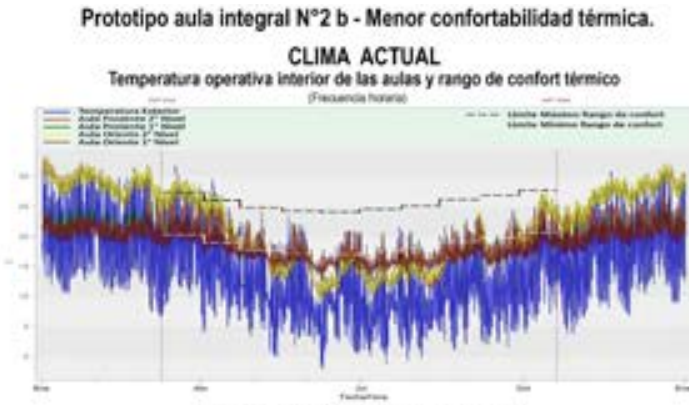

ESCENARIO CLIMATICO AÑO 2020

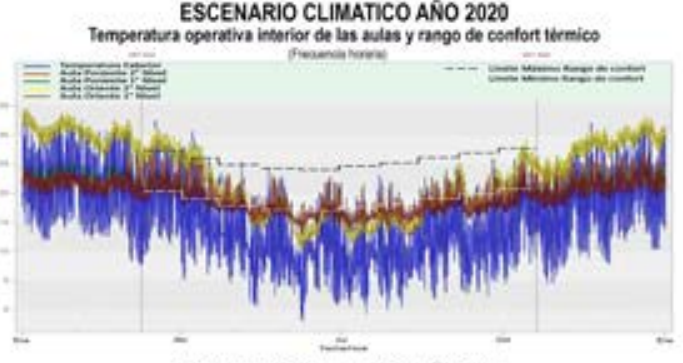

ESCENARIO CLIMATICO AÑO 2050

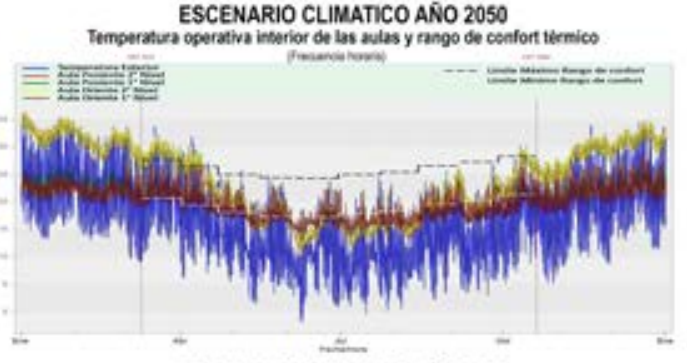

ESCENARIO CLIMATICO AÑO 2080

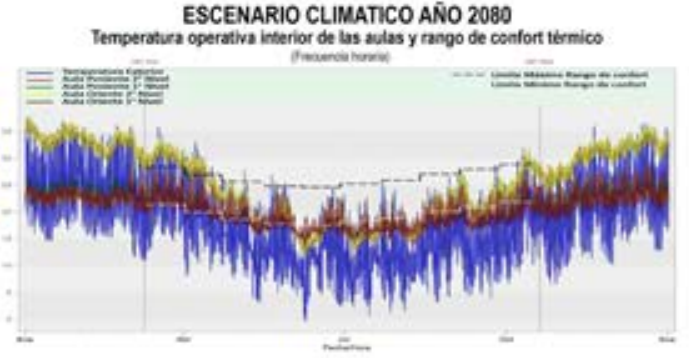


año 2080. Así, ambos prototipos, al ser evaluados en el tiempo, consiguen disminuir la brecha que se genera entre sus resultados.

Análisis de la temperatura interior de las aulas y rango de confort térmico para la Zona Sur Interior:

En la zona sur (Figura 9), las temperaturas exteriores son las más bajas, al compararlas con las zonas anteriores. Estas temperaturas aumentan al generarse una proyección futura de los cambios climáticos, pero de igual forma siguen siendo las más bajas de las zonas estudiadas.

Las aulas examinadas en esta zona exhiben una mayor estabilidad en el tiempo. Las bajas temperaturas al interior de las aulas, aunque aumentan con el tiempo por los cambios climáticos, no logran alcanzar el rango de confort térmico. Por tanto, se hace necesario incorporar algún sistema de calefacción, que aporte el calor necesario para los fríos meses de invierno.

En general, el porcentaje de disconfort es generado por bajas temperaturas al interior de las aulas, que no alcanzaron los rangos de confort. Esta situación se explica por extensos periodos con baja temperatura exterior, a diferencia de las altas temperaturas, que se producen en un periodo de tiempo menor, ya que el análisis no contempla los meses calurosos de enero y febrero que corresponden a vacaciones de verano. Incluso de esta forma, y debido a que estas aulas presentan una mayor aislación térmica que las evaluadas en las otras dos zonas, si aumenta la temperatura exterior, el riesgo de sobrecalentamiento se acrecienta.

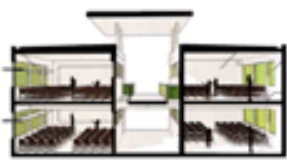

Prototipo aula integral $\mathrm{N}^{*} 1 \mathrm{~b}$ Mayor confortabilidad térmica.

Comparación del porcentaje de disconfort térmico en el tiempo. (Porcentaje de horna, en pericdo de coupaobion?
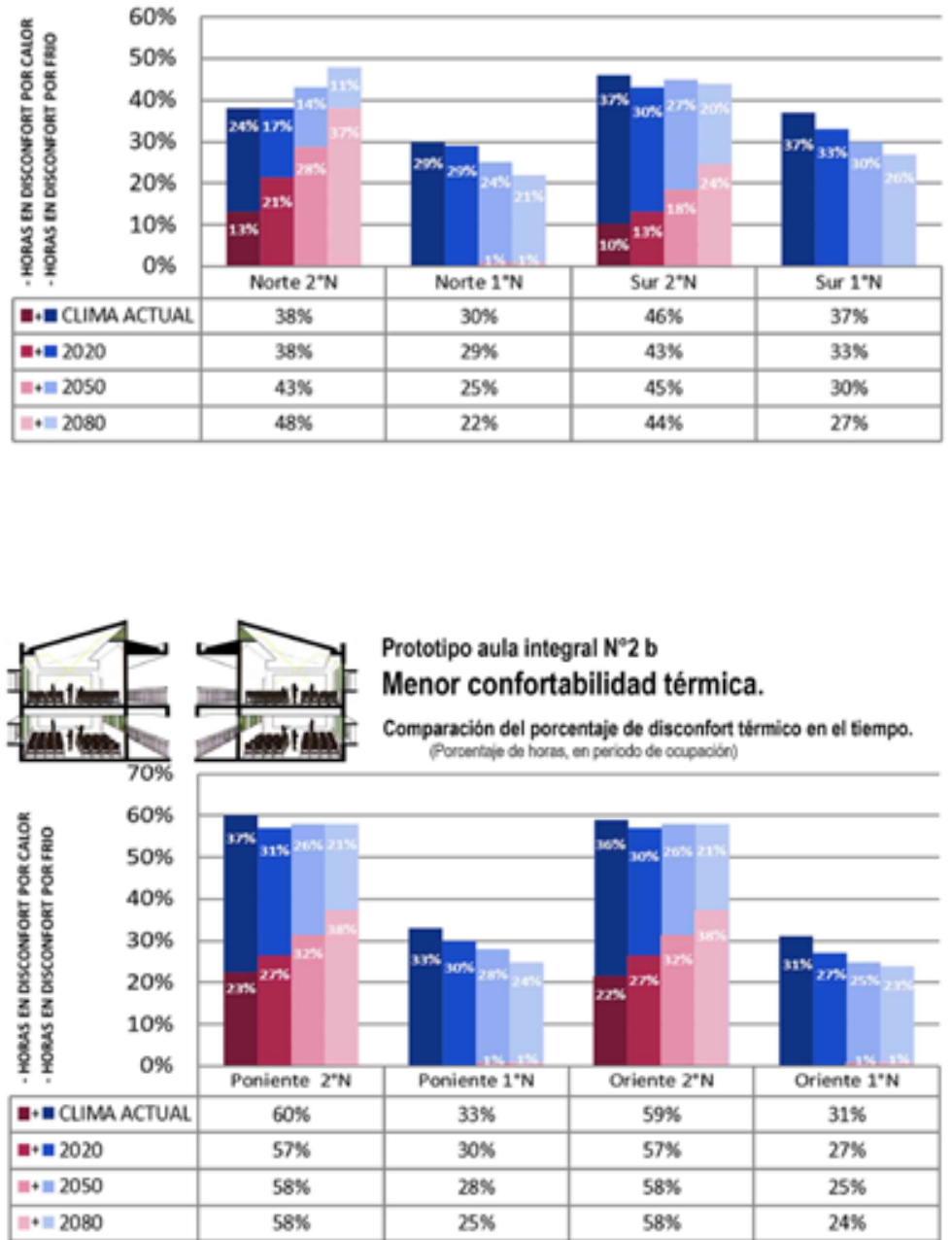
Otro factor que influye en el alto porcentaje de disconfort por bajas temperaturas es la selección del archivo climático utilizado en la simulación térmica, ya que los datos obtenidos para una condición climática actual, fueron generados con un archivo de promedios de temperatura de los años 1960 al 1991. Entendiendo que existe un cambio climático y el calentamiento global es un hecho, posiblemente se encuentran más cercanos a la realidad los resultados obtenidos para el año 2020, archivo climático que corresponde a una proyección basada en el archivo anterior, pero que constituye un promedio de temperaturas de los últimos 30 años. Dicha situación refuerza la importancia de trabajar con archivos actualizados y corroborados con estudios de campo.
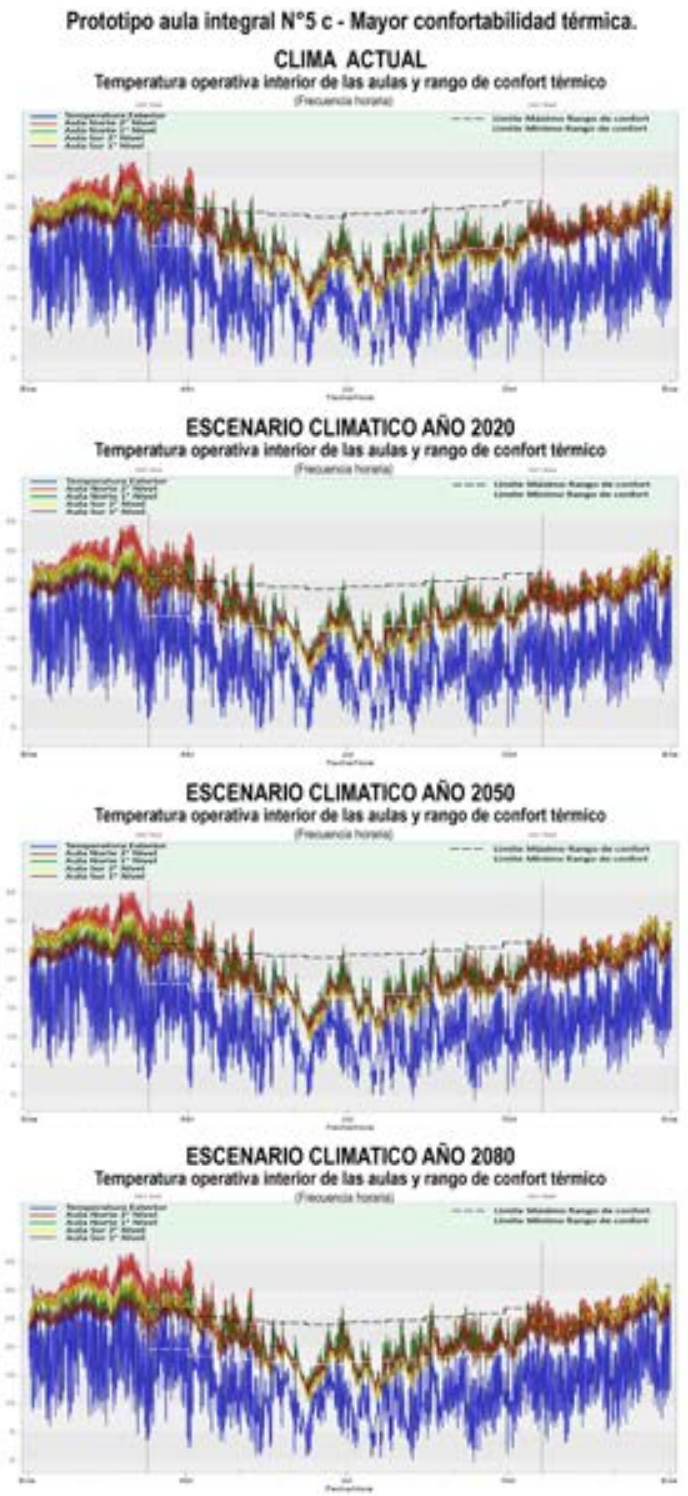

Análisis de los prototipos de aula con mayor y menor confortabilidad térmica para la Zona Sur Interior:

El análisis de las aulas en proyecciones de cambio climático, para la Zona Sur Interior (Figura 10), evidencia dos escenarios. El prototipo de aula $\mathrm{N}^{\circ} 5$, en condición climática actual, muestra el mejor resultado respecto al porcentaje de confortabilidad térmica. Sin embargo, con las proyecciones de cambio climático, estos resultados disminuyen de un 64\% a un 62\%, para el año 2080 . Por otro lado, el prototipo de aula $\mathrm{N}^{\circ} 2$, en condición climática actual, revela el peor resultado para esta zona, respecto al porcentaje de confortabilidad térmica. Este porcentaje se mantiene en el tiempo, alcanzando un $50 \%$ para el año 2080. Ambos prototipos, al ser evaluados en el tiempo, aumentan levemente la brecha que se genera entre sus resultados.

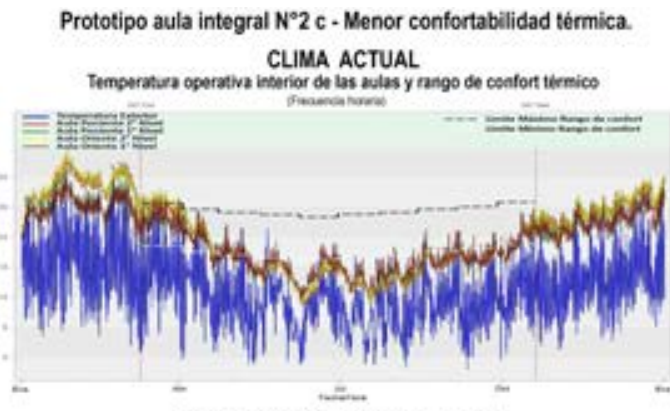

ESCENARIO CLIMATICO AÑO 2020

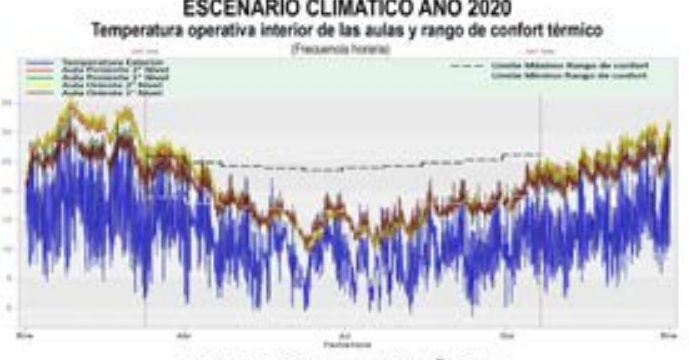

ESCENARIO CLIMATICO AÑO 2050

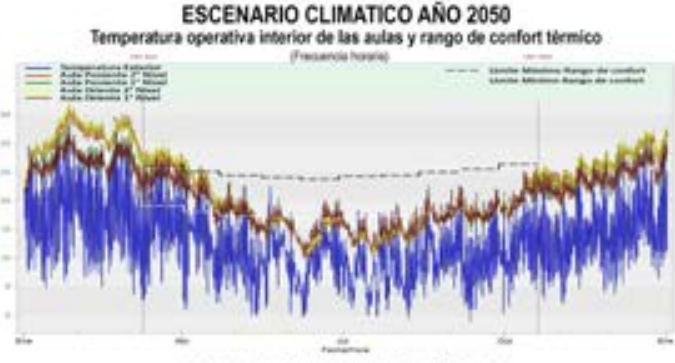

ESCENARIO CLIMATICO AÑO 2080

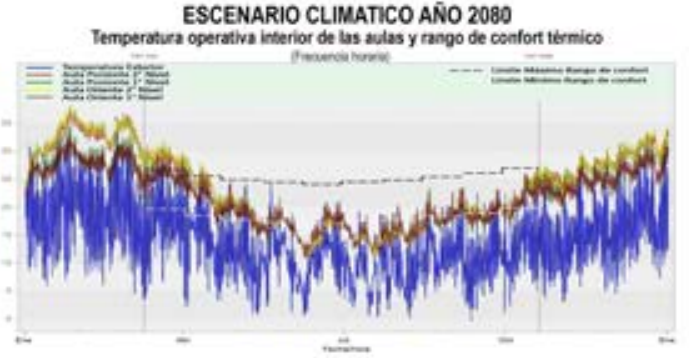



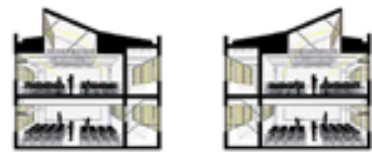

Prototipo aula integral $\mathrm{N}^{\circ} 5 \mathrm{C}$

Mayor confortabilidad térmica.

Comparación del porcentaje de disconfort termico en el tiempo. (Porsentape de horas, en periodo de ocupación)
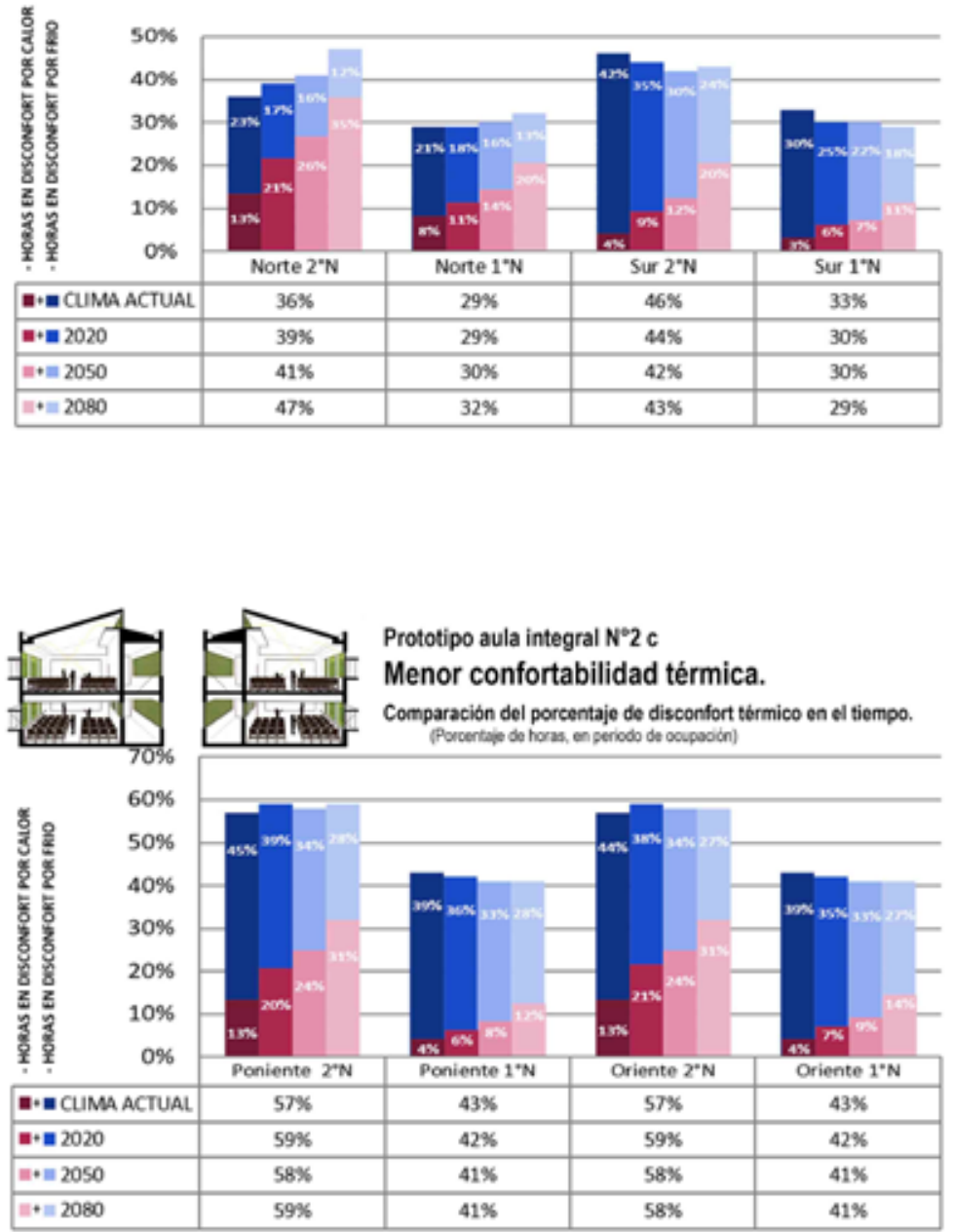

Figura 10 Análisis de aulas en proyecciones de cambio climático - Zona Sur Interior. Fuente: Elaboración de la autora.

\section{CONCLUSIONES}

Finalmente, de la investigación realizada, se concluye que, en la zona norte, las aulas evaluadas con mejor confortabilidad térmica en una condición climática actual disminuyen considerablemente sus resultados, al generarse una proyección en el tiempo. Situación contraria ocurre en las aulas con peores resultados, las cuales, al ser analizadas con proyecciones de cambio climático, aumentan levemente sus resultados. Esto provoca que se acorten las diferencias que existen entre estas aulas, con el primer análisis. La diferencia para el año 2080, donde la temperatura interior de las aulas se encuentra dentro del rango de confort térmico, corresponde a una semana y media más en condición de disconfort al interior de un aula, entre un prototipo y otro.
De ello se puede inferir que un buen diseño pasivo no garantiza un adecuado comportamiento térmico en el tiempo. Por ende, en la zona norte, el diseño del aula tiene una menor incidencia en los análisis, que en otras zonas climáticas. Con todo, es más fácil alcanzar buenos resultados, debido al tipo de clima y a las temperaturas de esta zona. En promedio, estas reflejan ser las aulas que presentan los mejores resultados, de las tres zonas climáticas evaluadas.

En la zona centro, los análisis muestran que con el tiempo se genera un sobrecalentamiento al interior de las aulas, en un corto periodo del año. Las temperaturas alcanzadas en los meses calurosos son bastante altas, pero por un periodo reducido de tiempo; de todas maneras, se trata de condiciones ambientales muy inadecuadas para los estudiantes. Lo mismo sucede en 
el corto periodo de invierno, donde las temperaturas alcanzan mínimas extremas. La diferencia de porcentaje en condición de confort entre el prototipo mejor y peor evaluado implica que los estudiantes se encontrarán alrededor de tres semanas más en condición de disconfort en las aulas del prototipo $\mathrm{N}^{\circ} 2$.

En esta misma zona climática se requiere de sistemas complementarios que regulen la temperatura al interior de las aulas. Los resultados indican que, en el caso de incorporar algún sistema de calefacción, se necesitará menos tiempo a medida que los años transcurran. Esto no ocurriría con los sistemas de enfriamiento, los cuales se utilizarían más cada año.

En la zona sur, la diferencia que existe entre los resultados de las aulas mejor y peor evaluadas para el año 2080 se traduce en un mes y medio más durante el cual los estudiantes se encontrarán en condición de disconfort. Esta diferencia es la más alta de entre las tres zonas climáticas estudiadas. En consecuencia, un buen diseño entregaría en esta zona una considerable diferencia en la cantidad de tiempo en que los estudiantes se encuentren en un ambiente confortable. En general, las aulas con orientación norte y grandes ventanas hacia esa orientación logran disminuir las bajas temperaturas en invierno. Además, en los meses calurosos, estrategias pasivas que ayudan a controlar el aumento de temperatura por ganancias solares, como ventanas con protecciones solares, aleros, entre otras, logran disminuir el riesgo de sobrecalentamiento, especialmente en el segundo nivel.

En esta zona resulta esencial incorporar un sistema de calefacción, ya que los mejores resultados bordearon el $60 \%$ de horas en condición de confort, para el año 2080. Esto significa que, en un año, los estudiantes permanecen casi la mitad del tiempo en un ambiente muy poco confortable. No obstante, al incorporar algún sistema de calefacción, un adecuado diseño pasivo de aula, podría generar un enorme ahorro en el consumo energético.

En resumen, los tres prototipos que presentaron mejor comportamiento térmico en condición climática actual sufrieron grandes variaciones al aplicárseles una proyección de cambio climático. Si bien estas variaciones fueron tanto positivas como negativas, para las tres zonas climáticas estudiadas, estos tres prototipos son los que presentan mayor porcentaje de horas en que la temperatura al interior de las aulas se encuentra dentro del rango de confort térmico. Por ello, se transforman en posibles referentes para nuevos proyectos educativos en cada una de las tres zonas climáticas examinadas, que evidentemente pueden contribuir a mejorar el confort térmico, incorporando sistemas de calefacción o enfriamiento de bajo consumo energético.

Dado lo anterior, es fundamental recalcar la importancia del estudio y determinación de criterios de confort térmico. Estos criterios son necesarios para diseñar edificaciones pensadas en los diferentes climas y a lo largo del tiempo, donde la calidad del ambiente interior de un aula esté enfocada en un adecuado desarrollo del aprendizaje en los estudiantes. Así, como país, se requiere la implementación de normativas que establezcan y garanticen un estándar de calidad ambiental al interior de las aulas. En definitiva, para muchos casos, son las normas las que determinan la manera en que se diseñan los espacios.

\section{REFERENCIAS BIBLIOGRÁFICAS}

ARMIJO, Gabriela; WHITMAN, Christopher J. y CASALS, Roberto. Post-Occupancy Evaluation of State Schools in 5 Climatic Zones of Chile, Gazi University Journal of Science, 2011, vol. 24, $n^{\circ} 2$, pp. 365-374.

ASHRAE 55-2017 (American Society of Heating, Refrigerating and Air-Conditioning Engineers). ANSI/ ASHRAE 55-2017: Thermal Environmental Conditions for Human Occupancy, Atlanta,2017.

BATIZ, Eduardo; GOEDERT, Jean; MORSCH, Junir Junior; KASMIRSKI, Pedro y VENSKE, Rafael. Avaliação do conforto térmico no aprendizado: estudo de caso sobre influência na atenção e memória, Produção, 2009, vol. $19, n^{\circ} 3$, pp. 477-488.

CITEC UBB. Guía de eficiencia Energética para Establecimientos Educacionales. $1^{\circ}$ ed. Santiago, 2012.

DIRECCIÓN METEOROLÓGICA DE CHILE. Resumen climático Chile - 2016. Santiago, 2016.

\section{DIRECCIÓN METEOROLÓGICA DE CHILE. Reporte anual} de la evolución del clima en Chile, 2017. Santiago, 2018.

IPCC (Intergovernmental panel on climate change). Global Warming of $1.5^{\circ} \mathrm{C}$ an IPCC special report on the impacts of global warming of $1.5^{\circ} \mathrm{C}$ above pre-industrial levels and related global greenhouse gas emission pathways, in the context of strengthening the global response to the threat of climate change, sustainable development, and efforts to eradicate poverty. 2018.

MOLINA, C. y VEAS, L. Evaluación del confort térmico en recintos de 10 edificios públicos de Chile en invierno, Revista de la Construcción, 2012, vol.12, n²2, pp. 27-38.

RUBIO-BELLIDO, Carlos y PÉREZ-FARGALLO, Alexis. Optimization of annual energy demand in office buildings under the influence of climate change in Chile. Energy [en línea], 2016, vol. 114, pp. 569-585. DOI: https://doi.org/10.1016/j.energy.2016.08.021

TREBILCOCK, Maureen; SOTO, Jaime; FIGUEROA Rodrigo y PIDERIT, Beatriz. Metodología para el diseño de edificios educacionales confortables y resilientes, Revista AUS, 2016, vol. 20, pp. 70-76.

TREBILCOCK, Maureen; SOTO-MUÑOZ, Jaime; YAÑEZ, Miguel y FIGUEROA, Rodrigo. The right to comfort: A field study on adaptive thermal comfort in free-running primary schools in Chile, Building and Environment [en línea], 2017, vol. 114, pp. 455-469. DOI: https://doi. org/10.1016/j.buildenv.2016.12.036

UNEP (United Nations Environment Programme). Building Design and Construction: Forging Resource Efficiency and Sustainable Development, 2012. 